\title{
Perceived Satisfaction of Public Health Facilities' with the Quality of Logistics Service Provided by Pharmaceutical Fund and Supply Agency Bahirdar Hub, Northwest Ethiopia: Descriptive Study
}

\section{Tefera BB*, Kebede B and Getachew M}

Debre Markos University, College of health science, MSc in Pharmaceutical Supply Chain Management, Ethiopia

*Corresponding author: Bereket Bahiru Tefera, Debre Markos University, College of health science, MSc in Pharmaceutical Supply Chain Management, Postal Code: 269, Ethiopia, Tel:

\section{Research Article}

Volume 4 Issue 6

Received Date: October 25, 2021

Published Date: November 11, 2021

DOI: $10.23880 /$ jqhe-16000246 +251909881252; Email: brktbahiru@gmail.com

\section{Abstract}

Aim: This study aimed to investigate the satisfaction of public health facilities in the quality of logistics services received from the Pharmaceutical Fund and Supply Agency Bahirdar hub.

Methodology: A descriptive research design has been used for assessing satisfaction. All hospitals in the study area were selected purposively and simple random sampling with a lottery method was used to pick health centers from the sampling frame. A total of 32 health facilities (i.e. 6 hospitals and 26 health centers) have been chosen for this research. Epidata software and SPSS version 20 were used for data entry and analysis, respectively. Frequency distribution, arithmetic means, and percentages were calculated.

Result: This research discovered that 41(64.1\%) of respondents were neither satisfied nor dissatisfied, while 19(29.7\%) considered themselves as 'satisfied' with the overall quality of the logistics services they received. Besides, $3(4.7 \%)$ of the respondents said they were 'dissatisfied' with the service and 1(1.6\%) was highly dissatisfied with the service.

Conclusion: The overall perceived satisfaction of public health facilities with the quality of logistics service given by the Pharmaceutical Fund and Supply Agency Bahirdar hub was in the middle of the continuum, with the mean score close to the 5-Likert scale midpoint.

Keywords: Public Health Facilities; Quality Of Logistic Service; Pharmaceutical Fund and Supply Agency; Customer Satisfaction; Perceived Satisfaction

Abbreviations: LPLS: Integrated Pharmaceutical Logistics System; LIAT: Logistics Indicators Assessment Tool; PFSA: Pharmaceutical Fund and Supply Agency; PLMP: Pharmaceutical Logistics Masters Plan; SD: Standard Deviation.

\section{Background}

Most scholars describe logistics services as the most critical elements that can help to achieve substantial customer satisfaction; however, managing the quality of logistics services is a difficult task [1]. Logistics is the process of planning, implementing, and controlling procedures for the safe and successful transport and storage of goods, and related information, from the point of origin to the point of consumption [2,3]. Usually, logistics management practices include inbound and outbound transportation management, fleet management, warehousing, material processing, order processing, inventory control, and supply and demand planning $[3,4]$. The rapid development of the logistics system 
will help to increase the distribution of goods within a short timeframe and the economic growth rate [5]. Recently, the basic definition of logistics service management has changed in two main ways: shifting from 'attention to the internal impact of success (e.g., internal efficiency including labor productivity and profits) to external consequences' (e.g., consumer satisfaction) and changing from 'focusing on the system to focusing on the process as part of the supply chain" [6]. The logistics service involves practices used to handle customer feedback and enhance customer satisfaction $[7,8]$. Dimensions of the quality of the logistics service that can be measured from a customer satisfaction perspective include the reporting and requisition procedure, capability of the staff, quality of the information, management of order discrepancies, product availability, service accuracy, timeliness, and product delivery condition [1].

The main metric for healthcare logistics services is customer satisfaction, and it is positively linked to the quality of the pharmaceutical logistics service [9]. The health logistics system is responsible for ensuring that every patient can access and use quality healthcare supplies [4]. Providing a complete healthcare service necessitates the availability of quality, safe, effective, and affordable medicines and supplies in adequate quantities at all times [10]. Despite this reality, Ethiopia's pharmaceutical logistics system has had many issues in the past, including inaccessibility, unaffordability, poor storage and inventory management, and unreasonable use [11-14]. In 2004, a national review of the performance of the existing public health pharmaceutical logistics system was conducted and several shortcomings and challenges were discovered. To solve these problems in public health facilities, the Pharmaceuticals Fund and the Supply Agency (PFSA) was established in 2007 by Proclamation No. 553/2007 based on the Pharmaceutical Logistics Master Plan (PLMP) $[15,16]$. The agency is mandated to provide all public health facilities with affordable and high-quality pharmaceuticals in a sustainable way and to ensure rational use. Therefore, an integrated pharmaceutical logistics system (IPLS) has been developed and implemented since 2010 to execute its mandate effectively and efficiently $[12,14,15]$. IPLS is the primary mechanism by which all public health facilities found in Ethiopia get pharmaceuticals to fulfill the six rights of the logistics system through the implementation of effective, efficient, and easy-to-use systems [4,14]. An assessment of various customer satisfaction metrics for the quality of logistics services in the health care system is necessary for continuous service improvement and the achievement of the best clinical outcome. Besides, assessing the logistics service quality from the customer perspective is usually more comprehensive $[17,18]$. This study was therefore attempted to investigate the satisfaction of public health facilities in the quality of logistics services received from PFSA Bahirdar hub.

\section{Methods}

A descriptive research design was used to assess the level of satisfaction public health facilities with the quality of logistics service received from the PFSA Bahirdar hub. This study was conducted in public health facilities located in the West Gojjam zone, one of the most densely populated areas in the State of Amhara, Ethiopia. The capital city of this zone is Finoteselam town, which is $174 \mathrm{~km}$ from Bahirdar and 481 $\mathrm{km}$ from Addis Ababa. An estimated 2.2 million inhabitants live in this region. In the study area, there were 130 health centers and 6 primary hospitals. The data collection was carried out in selected public health facilities located in the West Gojjam zone from 28 April/20, 2019 to - 20 June/2019.

All public health facilities in the West Gojjam zone were the study populations of this study. These public health facilities were all health centers, primary and general hospitals located in the study area. Public health facilities, getting pharmaceutical products from PFSA Bahirdar hub as the main supplier and started providing healthcare services at least 6 months before the data collection period and were included in this study. Besides, the pharmacy managers and pharmaceutical store managers who worked in their public health facilities for less than 6 months and were not on duty during the data collection period were excluded from this study.

All hospitals in the study area were selected purposively and simple random sampling with a lottery method was used to pick health centers from the sampling frame, which was prepared based on the inclusion criteria. Under the Logistics Indicators Assessment Tool (LIAT) of the USAID Delivery Project, a minimum of $15 \%$ of healthcare institutions within the study area is recommended for the determination of samples [19]. However, all hospitals and $20 \%$ of health centers located in the West Gojjam zone have been selected for this research. A total of 32 health facilities (i.e. 6 hospitals and 26 health centers) have been chosen for this research since a total of 130 health centers have been found in this area, taking 20 percent of them into account. The pharmacy department head and pharmaceutical store manager (both were pharmacists) in each selected public health were chosen purposively to fille the questionnaire.

The questionnaire used to assess satisfaction with quality logistics services was taken from the questions that were examined and validated by various related literature [1]. Respondents were asked to gauge their satisfaction level as well as to express their overall verdict using a 5-point quantitative scale of the form: highly satisfied, satisfied, neutral, dissatisfied, and highly dissatisfied. The questionnaire had thirty-three questions grouped into two parts. Thirty-three questions in the questionnaire were 
grouped into two sections. There were three questions in the first section and it was supposed to collect demographic information regarding public health facilities. In the second part, twenty-nine questions, prepared with a five-point Likert scale, were asked to determine the extent of satisfaction with the questions prepared to assess the level of satisfaction with the quality of the logistics services received.

The data were collected through the administration and collection of the questionnaires under the supervision of the data collector. The data were checked for completeness and then entered into Epi Data software. After data cleaning was done, the data were analyzed with the Statistical Package for Social Science (SPSS) programs version 20. Frequency distribution, arithmetic means, standard deviation (S.D), and percentages were computed.

The quality of the data was ensured by properly preparing and pretesting the questionnaires. A pretest was conducted on 5 percent of the total sample size (i.e., 2 public health facilities) and an acceptable adjustment of the questionnaires was made to increase the reliability and accuracy of the data collection instruments. Cronbach's alpha was estimated to measure the reliability of the final questionnaires used for data collection and was 0.953 . The accuracy of the data was also ensured by proper categorization and coding of the questionnaires, giving instructions to respondents about the questionnaires, and evaluation of the completeness of the filled questionnaires before analysis.

The variables measured by this research include procedure, contact, information, discrepancy, availability, accuracy, timeliness, and condition of delivery. Procedures: refers to the effectiveness and easiness of the reporting and ordering procedures used by PFSA Bahirdar hub, as well as the flexibility of the procedures in the event of demand changes. Contact: it is related to the expertise and willingness of PFSA Bahirdar hub staff to solve product or service issues. It also explores the efforts made by contact workers to understand specific business situations and their overall conduct. Information: This refers to the accuracy, availability, and completeness of the logistics-related information issued by the PFSA Bahirdar hub. Discrepancies: It examines the efforts of the PFSA Bahirdar hub to correct and respond to errors in requisition, as well as the appropriateness of the reporting process. Availability: It refers to the availability of requested pharmaceutical products at the PFSA Bahirdar hub and it also refers to the handling of a variety of pharmaceutical products in response to the unexpected demand increase. Accuracy: it refers to whether the pharmaceutical product meets both the specifications and technical requirements of the order, as well as the frequency of delivery of incorrect products or incorrect amounts from PFSA Bahirdar hub. Timeliness: It refers to the PFSA Bahirdar hub speed to process orders, and the time taken between order requests and receipts. Condition: It examines the effort of the PFSA Bahirdar hub to supply customers with actual damage-free pharmaceutical products and accurate distribution documents.

According to the National Research Ethical Review Guideline of Ethiopia, where the purpose of the study is to examine government programs designed to provide the public service and where information has been collected by the investigator in such a way that it is impossible to identify the study participants, it is exempted from ethical review [20]. Before starting data collection, verbal consent was obtained from all respondents, and confidentiality of the information was assured to them. Since the study involves no more than minimal risk to participants, verbal informed consent is acceptable under the National Research Ethical Review Guideline [20].

\section{Result}

\section{Demographic Characteristics}

To determine the degree to which public health facilities were pleased with the quality of the logistics services provided by the PFSA Bahirdar hub, 64 questionnaires were distributed to 32 public health facilities and all questionnaires were collected and filled out accordingly. The response rate, therefore, was $100 \%$.

The majority of public health facilities included in this research, 26 (82.25\%), were health centers (Table 1). Furthermore, $17(53.13 \%)$ of all health centers included in the study were antiretroviral sites. Besides, all of the hospitals included in this analysis were also antiretroviral sites.

\begin{tabular}{|c|c|c|c|c|}
\hline \multicolumn{2}{|c|}{ Type of health facility } & Frequency & Percentage (\%) & \multirow{2}{*}{ Total Percentage (\%) } \\
\hline \multirow{2}{*}{ Health center } & ART site & 17 & 53.13 & \multirow{2}{*}{82.25} \\
\cline { 2 - 4 } & Non-ART site & 9 & 28.12 & \multirow{2}{*}{100} \\
\hline Hospitals & ART site & 6 & 18.75 & \\
\hline Total & Non-ART site & 0 & 0 & \\
\hline
\end{tabular}

Perceived Satisfaction with the Overall Quality of Logistics Services

Table 1: Demographic Characteristics of health facilities included in the study. 
To assess the level of satisfaction of public health facilities with the overall quality of the logistics services provided by PFSA Bahirdar hub, respondents were asked to rate their level of satisfaction using a 5-point Likert scale (1 = Highly Dissatisfied, 2 = Dissatisfied, $3=$ Neutral, $4=$ Satisfied, and $5=$ Highly Satisfied). The majority of respondents,
41(64.1\%), reported being 'neutral,' while 19(29.7\%) considered themselves 'satisfied' with the overall quality of the logistics services they received from the PFSA Bahirdar hub (Table 2). Besides, 3(4.7\%) of the respondents said they were 'dissatisfied' with the service and $1(1.6 \%)$ was highly dissatisfied with the service.

\begin{tabular}{|c|c|c|c|}
\hline Likert scale & Frequency(N) & Percent (\%) & Cumulative Percent (\%) \\
\hline Highly dissatisfied & 1 & 1.6 & 1.6 \\
\hline Dissatisfied & 3 & 4.7 & 70.3 \\
\hline Neutral & 41 & 64.1 & 100 \\
\hline Satisfied & 19 & 29.7 & 100 \\
\hline Highly satisfied & 0 & 0 & \\
\hline Total & 64 & 100 & \\
\hline
\end{tabular}

Perceived Satisfaction with Procedure, Contact, and Timeliness.

Table 2: Perceived satisfaction on the overall quality of logistics service provided by PFSA Bahirdar hub.

As shown in Table 3, three questions were used to assess the perceived satisfaction of respondents with reporting and requisition "Procedure" and 37(54.7\%), 36(56.3\%), and $37(57.8 \%)$ of the respondents were satisfied with the effectiveness, simplicity, and versatility of the procedure employed by PFSA Bahirdar hub, respectively. Conversely, $10(15.6 \%), 7(10.9 \%)$, and $8(12.5 \%)$ of the respondents reported as being neutral for the effectiveness, easiness, and versatility of the procedure.

\begin{tabular}{|c|c|c|c|c|c|c|}
\hline \multirow{5}{*}{ Procedure } & $\begin{array}{c}\text { Highly } \\
\text { Dissatisfied }\end{array}$ & Dissatisfied & Neutral & Satisfied & $\begin{array}{c}\text { Highly } \\
\text { satisfied }\end{array}$ \\
\hline & $\begin{array}{c}\text { Effective overall reporting and requisition } \\
\text { procedure }\end{array}$ & $1(1.6)$ & $10(15.6)$ & $15(23.4)$ & $35(54.7)$ & $3(4.7)$ \\
\cline { 2 - 7 } & $\begin{array}{c}\text { Easy procedure for placing an order by } \\
\text { customer }\end{array}$ & $0(0)$ & $7(10.9)$ & $17(26.6)$ & $36(56.3)$ & $4(6.3)$ \\
\hline \multirow{5}{*}{$\begin{array}{c}\text { flexible procedure to accommodate } \\
\text { unexpectedly demand fluctuation }\end{array}$} & $1(1.6)$ & $8(12.5)$ & $17(26.6)$ & $37(57.8)$ & $1(1.6)$ \\
\hline & $\begin{array}{c}\text { Adequate staff's knowledge about the logistics } \\
\text { service they provide and the products they } \\
\text { handle }\end{array}$ & $3(4.7)$ & $11(17.2)$ & $24(37.5)$ & $26(40.6)$ & $0(0)$ \\
\cline { 2 - 7 } & $\begin{array}{c}\text { The staffs' ability to resolve logistics related } \\
\text { problems }\end{array}$ & $2(3.1)$ & $13(20.3)$ & $17(26.6)$ & $32(50.0)$ & $0(0)$ \\
\cline { 2 - 7 } & $\begin{array}{c}\text { The staff's efforts to understand customer's } \\
\text { logistics issues }\end{array}$ & $3(4.7)$ & $11(17.2)$ & $24(37.5)$ & $26(40.6)$ & $0(0)$ \\
\cline { 2 - 7 } & The staff's overall behavior & $1(1.6)$ & $7(10.9)$ & $15(23.4)$ & $34(53.1)$ & $7(10.9)$ \\
\hline \multirow{5}{*}{ Information } & Provide accuracy Logistics related information & $1(1.6)$ & $9(14.10$ & $19(29.7)$ & $33(51.6)$ & $2(3.1)$ \\
\cline { 2 - 7 } & The availability of logistics information & $2(3.1)$ & $10(15.6)$ & $13(20.3)$ & $37(57.8)$ & $2(3.1)$ \\
\cline { 2 - 7 } & Provide the complete information & $2(3.1)$ & $7(10.9)$ & $20(31.3)$ & $34(53.1)$ & $1(1.6)$ \\
\hline
\end{tabular}

Perceived Satisfaction with Order Discrepancy, Availability, and Delivery Accuracy

Table 3: Descriptive Statistics of 5- Likert Scale of Procedure, Contact, and Information.

As indicated in Table 3, four questions were asked to determine the perceived satisfaction of respondents with the quality of "contact (staff)" of PFSA Bahirdar hub and $26(40.6 \%)$ of the respondents were satisfied with the staff's knowledge regarding the logistics service they provided and the products they handle, while $24(37.5 \%)$ of the respondents were neutral. Along with this, $32(50.0 \%)$ of the respondent were satisfied with the ability of the staff 
to address logistics-related issues, while $17(26.6 \%)$ of the respondents were neutral. 26(40.6\%) of the respondents were satisfied with the efforts of the workers to understand the logistics issues from the customers' perspective. Among all respondents, 34(53.1\%) of them were satisfied with the overall conduct of works while 15(23.4\%) were neutral.

Three questions were asked to assess the perceived satisfaction of respondents with the quality of logistics "information" provided by PFSA Bahirdar hub and 33(51.6\%) of the respondents were satisfied with the accuracy of logistics-related information. In contrast, $1(1.6 \%)$ of them were highly dissatisfied with the accuracy of logisticsrelated information received. Besides this, $37(57.8 \%)$ of the respondents were satisfied with the availability of logisticsrelated information needed for decision making. And $34(53.1 \%)$ of the respondents were indeed satisfied with the completeness of the information while $1(1.6 \%)$ of the respondents appeared highly satisfied.

\begin{tabular}{|c|c|c|c|c|c|c|}
\hline & & $\begin{array}{c}\text { Highly } \\
\text { Dissatisfied }\end{array}$ & Dissatisfied & Neutral & Satisfied & $\begin{array}{c}\text { Highly } \\
\text { satisfied }\end{array}$ \\
\hline \multirow{3}{*}{ Discrepancy } & The effort to correct order discrepancies & $0(0)$ & $18(28.1)$ & $16(25.0)$ & $28(43.8)$ & $2(3.1)$ \\
\hline & $\begin{array}{c}\text { Easy and suitable procedure set for reporting } \\
\text { order discrepancies to customer }\end{array}$ & $0(0)$ & $12(18.8)$ & $22(34.4)$ & $28(43.8)$ & $2(3.1)$ \\
\hline & $\begin{array}{l}\text { Always report the order discrepancy as fast } \\
\text { as possible to the customer }\end{array}$ & $3(4.7)$ & $22(34.4)$ & $20(31.3)$ & $17(26.6)$ & $2(3.1)$ \\
\hline \multirow{5}{*}{ Availability } & $\begin{array}{l}\text { The distance between the health facility and } \\
\text { PFSA is short }\end{array}$ & $4(6.3)$ & $13(20.3)$ & $17(26.6)$ & $24(37.5)$ & $6(9.4)$ \\
\hline & $\begin{array}{l}\text { Responsiveness to unexpected demand } \\
\text { increment }\end{array}$ & $3(4.7)$ & $17(26.6)$ & $15(23.4)$ & $27(42.2)$ & $2(3.1)$ \\
\hline & Requested products availability & $9(14.1)$ & $27(42.2)$ & $17(26.6)$ & $9(14.1)$ & $2(3.1)$ \\
\hline & $\begin{array}{l}\text { full amount re-supply of the quantity } \\
\text { requested }\end{array}$ & $10(15.6)$ & $22(34.4)$ & $19(29.7)$ & $13(20.3)$ & $0(0)$ \\
\hline & Handling variety products & $5(7.8)$ & $17(26.6)$ & $17(26.6)$ & $25(39.1)$ & $0(0)$ \\
\hline \multirow{5}{*}{ Accuracy } & $\begin{array}{c}\text { The products delivered conform to requested } \\
\text { standards and specifications }\end{array}$ & $4(6.3)$ & $6(9.40$ & $13(20.3)$ & $39(60.9)$ & $2(3.1)$ \\
\hline & $\begin{array}{l}\text { Handling products met the requested } \\
\text { technical requirements }\end{array}$ & & $10(15) 6$. & $15(23.4)$ & $37(57.8)$ & $2(3.1)$ \\
\hline & $\begin{array}{l}\text { Product delivery rarely containing wrong } \\
\text { items }\end{array}$ & $4(6.3)$ & $9(14.1)$ & $10(15.60$ & $38(59.4)$ & $3(4.7)$ \\
\hline & $\begin{array}{c}\text { Obsolete and expired products rarely } \\
\text { delivered }\end{array}$ & $6(9.4)$ & $11(17.2)$ & $17(26.6)$ & $28(43.8)$ & $2(3.1)$ \\
\hline & $\begin{array}{l}\text { Always correct requested quantities } \\
\text { delivered }\end{array}$ & $3(4.7)$ & $15(23.4)$ & $16(25.0)$ & $28(43.8)$ & $2(3.1)$ \\
\hline
\end{tabular}

Perceived Satisfaction with Timeliness, and Delivery Condition.

Table 4: Descriptive Statistic of 5-Likert Scale on Order Discrepancy, Availability, and Accuracy.

As can be seen in Table 4, the respondents were asked three questions that were used to assess the extent of perceived satisfaction with order "discrepancy." Among all respondents, $28(43.8 \%)$ were satisfied with the effort made by the PFSA Bahirdar hub to correct the order discrepancies submitted by customers. Besides, 28 (43.8\%) of the respondents were satisfied with the suitability of the procedure being used by PFSA Bahirdar hub to communicate order discrepancies. Of all respondents, 22 (34.4\%) were dissatisfied with the pace of the PFSA Bahirdar hub announcing an order discrepancy to their client, whereas 20
$(31.3 \%)$ were neutral.

Five questions were asked to determine the degree of perceived satisfaction with the pharmaceutical product "availability" at PFSA Bahirdar hub and 24(37.5\%) of the respondents were satisfied with the distance between their health facility and the PFSA Bahirdar hub. Besides, $27(42.2 \%)$ of the respondents were satisfied with the PFSA Bahirdar hub's responsiveness to the unexpected demand change. On the other hand, 27(42.2\%) of the respondents have been dissatisfied with the availability of requested 
products at PFSA Bahirdar hub. Similarly, 22(34.4\%) of the respondents were dissatisfied with the PFSA Bahirdar hub about replenishing the full quantity of each item requested by the customers. However, 25(39.1\%) of them were satisfied with the product variety being handled by the PFSA Bahirdar hub.

As can be seen in Table 4, the respondents were asked four questions to determine their satisfaction with the "accuracy" of the logistics services provided by the PFSA Bahirdar hub. Of all respondents, 39 (60.9\%) were satisfied with the delivery of the pharmaceuticals' compliance with the requested standards and specifications. And, 37 (57.8\%) of them were satisfied with the technical specifications of the products meeting the customer's preferences. Additionally, $38(59.4 \%)$ of them have been satisfied with the perfection of the distribution of the pharmaceutical (containing correct products) by the PFSA Bahirdar hub. 28(43.8\%) of the respondents were satisfied with the delivery of non-obsolete and unexpired pharmaceutical products. As well, 28(43.8\%) of the respondents were satisfied with the delivery of the products with the correct requested quantity.
Three questions have been asked to determine the level of their perceived satisfaction with the "timeliness" of logistics services provided by PFSA Bahirdar hub. Among all respondents, 25(39.1\%) of them were satisfied with the delivery pace of the requested pharmaceutical product. Nevertheless, 21(32.8\%) of them were dissatisfied with the consistency of the delivery time of pharmaceuticals products. Similarly, 20 (31.3\%) of respondents were satisfied with the delivery of pharmaceuticals at the agreed time.

As Table 5 indicates, respondents have been asked three questions to determine their perceived satisfaction with the delivery "condition" of pharmaceutical products. Of the respondents, $39(60.9 \%)$ were satisfied with the delivery of the damage-free products from the PFSA Bahirdar hub and $38(59.4 \%)$ were also satisfied with the low level of pharmaceuticals damage during the transportation from the PFSA Bahirdar hub. Besides, 44(68.8\%) of the respondents were satisfied with the correctness of the pharmaceuticals distribution documents.

\begin{tabular}{|c|c|c|c|c|c|c|}
\hline & & $\begin{array}{c}\text { Highly } \\
\text { Dissatisfied }\end{array}$ & Dissatisfied & Neutral & Satisfied & $\begin{array}{c}\text { Highly } \\
\text { satisfied }\end{array}$ \\
\hline \multirow{4}{*}{ Timeliness } & $\begin{array}{c}\text { Short length of time between product } \\
\text { ordering and receiving }\end{array}$ & 0 & $18(28.1)$ & $19(29.7)$ & $25(39.1)$ & $2(3.1)$ \\
\cline { 2 - 7 } & Consistent product delivery time & $3(4.7)$ & $21(32.8)$ & $19(29.7)$ & $20(31.3)$ & $1(1.6)$ \\
\cline { 2 - 7 } & Always products delivered on agreed time & $2(3.1)$ & $19(29.7)$ & $20(31.3)$ & $20(31.3)$ & $3(4.7)$ \\
\hline \multirow{3}{*}{ Condition } & Always damage-free products delivered & $1(1.6)$ & $7(10.9)$ & $12(18.8)$ & & $5(7.8)$ \\
\cline { 2 - 7 } & $\begin{array}{c}\text { low level of product damage during } \\
\text { transportation }\end{array}$ & $0(0)$ & $5(7.8)$ & $13(20.3)$ & $38(59.4)$ & $8(12.5)$ \\
\cline { 2 - 7 } & Always correct delivery documents & 0 & $5(7.8)$ & $8(12.5)$ & $44(68.8)$ & $7(10.9)$ \\
\hline
\end{tabular}

Overall Mean Perceived Satisfaction for Each Quality of Logistics Service Dimension.

Table 5: Descriptive Statistics of the 5-Likert scale of Timeliness, and Delivery Condition.

\begin{tabular}{|c|c|c|c|c|c|}
\hline Quality of Logistics Services Dimensions & Mean & Mode & S.D & Min & Max \\
\hline Procedure & 3.501 & 4 & 0.69 & 1.76 & 5 \\
\hline Contact & 3.388 & 3.5 & 0.586 & 1.5 & 4.25 \\
\hline Information & 3.411 & 4 & 0.709 & 1 & 4.67 \\
\hline Discrepancy & 3.144 & 3 & 0.729 & 1.67 & 5 \\
\hline Availability & 2.885 & 2.4 & 0.67 & 1.2 & 4 \\
\hline Accuracy & 3.336 & 4 & 0.633 & 1.6 & 4.8 \\
\hline Timeliness & 3.051 & 2.67 & 0.772 & 1.33 & 4.33 \\
\hline Condition & 3.749 & 4 & 0.641 & 1.67 & 5 \\
\hline
\end{tabular}

Table 6: Overall Mean Perceived Satisfaction for Each Quality of Logistics Service Dimension.

As shown in Table 6, across all the dimensions of the quality of the logistics service evaluated in this research, the degree of perceived satisfaction of the respondents with the delivery condition of pharmaceuticals was found to be higher 
with a mean score and standard deviation of $3.749(0.641)$ followed by the reporting and ordering procedure employed by PFSA Bahirdar hub with a mean score and standard score of 3.501(0.690). The overall mean score and standard deviation of the other dimensions of logistics services, such as information, contact, accuracy, discrepancy, and timeliness, were 3.411(0.709), 3.388(0.586), 3.336(0.633), 3.144(0.729), and 3.051(0.772), respectively. In contrast, the satisfaction of the respondents with the "availability" of pharmaceuticals at the PFSA Bahirdar hub was the quality of the logistics service dimension with the least overall mean score and standard deviation of 2,885(0.670).

\section{Discussion}

Assessing customer satisfaction is one of the critical mechanisms for advancing the efficiency of various approaches to logistics in the health care system [21]. Therefore, this study focused on measuring the satisfaction of public health facilities with the logistics services they were receiving from the PFSA Bahirdar hub.

This study discovered that the majority of the respondents $(64.1 \%)$ were neither satisfied nor dissatisfied with the overall quality of logistics services provided by the PFSA Bahirdar hub. This suggests that the satisfaction level was in the middle of the 5-Likert scale. However, $29.6 \%$ of the respondents expressed that they were satisfied with the overall quality of the logistics service they received. The remaining $4.7 \%$ and $1.6 \%$ of the respondents reported being dissatisfied and very dissatisfied, respectively. Therefore, more than $70.4 \%$ of the total participants were not pleased with the overall quality of logistics services they received from the PFSA Bahirdar hub, which has a tremendous effect on the quality of basic healthcare services being provided by the public health facilities.

The logistics service dimension with the second-highest overall mean value reported in this study was the reporting and requisition "procedure" employed by PFSA Bahirdar hub for serving public health facilities, with a mean value of 3.501. This shows that the PFSA Bahirdar hub employed effective and user-friendly procedures for reporting information and placing the order, and the procedure set out by PFSA Bahirdar hub was versatile to accommodate the unexpected variance in demand. The use of effective and efficient retrieval procedures by medical suppliers has notable effects on the customer's satisfaction and the quality of services provided by healthcare organizations, thereby reducing procurement costs and distribution of goods [22,23].

The "contact" (staff) of the PFSA Bahirdar hub was the dimension with the fourth-highest overall mean value. It was one of the dimensions with a mean value very close to the midpoint of the 5-Likert scale (mean $=3.0$ ), with a mean value of 3.388. It suggests that the customers of the PFSA Bahirdar hub were not significantly pleased with the knowledge and behavior of the staff, therefore, PFSA Bahirdar hub should take appropriate measurements, e.g., providing training to its staff, to improve their knowledge and attitude. This finding was somewhat lower than the finding of a study conducted in India and Palestine [24,25]. A study done in Indonesia concludes that employee knowledge and behavior can directly affect customer satisfaction and fidelity [26].

The dimension with the third-highest overall mean value was logistics-related "information" provided by PFSA Bahirdar hub, with a mean value of 3.411. Although it is larger than the midpoint of the 5-Likert scale continuum, it is still close to the midpoint; therefore, the PFSA Bahirdar hub should make a significant effort to improve the availability, accuracy, and completeness of the information it provides to customers. The result of a study done in Singapore, with a mean value of 3.85 , is almost similar to this study. Accessibility of quality information at the right time and place is important to ensure the continuous operation of the logistics process and is crucial to fostering trust among its customers [27].

Order "discrepancy" was the quality of the logistics services dimension with the sixth-highest overall mean value reported in this study and it was 3.144. This result is almost close to the midpoint of the 5-Likert scale, which is 3.0. It indicates that the respondents were not pleased with the procedure that is being used by the PFSA Bahirdar hub to manage the order discrepancy coming from the customer, and the effort of PFSA Bahirdar hub to communicate with customers.

The dimension of quality of logistics services with the least mean score was the availability of pharmaceuticals (mean =2.875). This indicates that the availability of pharmaceuticals at the PFSA Bahirdar hub was not adequate to satisfy the demand of its customers, which are public health facilities. Besides, it implies that due to frequent drug shortages at public health facilities have been compromising the quality of the health care service. This finding was lower than studies done in India and Palestine with a mean of 3. 66 and 3.75, respectively [24,28]. However, this finding is consistent with the conclusion of a study done in Ethiopia, India, and China [29-31]. Ideally, frequent medicine stockout can happen due to inaccurate demand forecasting, limited government budget allocation, or inefficient budget utilization [32].

The "accuracy" of the overall logistics services provided by the PFSA Bahirdar hub is the dimension with the fifth-highest overall mean value, which is 3.336 and 
it is almost near to the midpoint of the 5-Likert scale that is 3.0. This demonstrates that the PFSA Bahirdar hub was delivering incorrect quantities and obsolete or near-expiry pharmaceuticals to their customers. This result agreed with studies done in Malaysia and Palestine [25,27].

The quality of logistics service's dimension with the seventh-highest overall mean value was the "timeliness" of logistics services, being provided by PFSA Bahirdar hub, with a mean value of 3.051. This value is at the midpoint of the 5-Likert continuum (mean-3.0) and it was lower than the finding of studies done in Singapore and Malaysia [18,27]. Moreover, this finding indicates that respondents were not happy with the length of the lead-time of pharmaceutical delivery from the PFSA Bahirdar hub. Having a logistics system with a speedy customer request fulfillment rate for shortening the lead time is the key to improve customer satisfaction, especially for customers like health care providers [33]. Pharmaceuticals are the key to provide basic health care services, therefore, they must be delivered at the right time to the right places [34].

Among the quality of logistics service dimensions assessed in this study, the "condition" of pharmaceutical delivery was the one with the highest overall mean value compared to the other dimensions (mean=3.740). This suggests that the effort made by the PFSA Bahirdar hub to distribute damage-free pharmaceutical products and correct delivery documents was satisfactory relative to other logistics activities. The finding of a study done in India, with a mean value of 4.30 , was slightly higher than this finding [24]. Pharmaceuticals can be damaged and become impotent or unsafe during transport if they are exposed to temperature or humidity beyond their specified range. Therefore, distributors have to make an appropriate effort to protect the pharmaceuticals, since it has an impact on both the quality and quantity of the product supplied to the health care providers [35].

Some of the limitations of this study include that it assessed only the public health satisfaction with the quality of logistics services, but it would be more comprehensive if the study evaluated which factors significantly affect satisfaction. Besides, this research assessed only the satisfaction of public health facilities, but it would be more complete if the research evaluated the factors that substantially affect satisfaction.

\section{Conclusions and Recommendations}

This study found out that the perceived satisfaction of public health facilities with the condition of pharmaceutical delivery received the highest mean score compared to the other seven dimensions, followed by procedure flexibility and effectiveness, information quality, staff quality, accuracy, order discrepancy handling, timeliness, and product availability sequentially. Besides, the pharmaceutical product availability was the dimension of quality of the logistics service with the least mean score. In general, the overall perceived satisfaction of public health facilities with the quality of logistics service given by Bahirdar PFSA hub was in the middle of the continuum, with the mean score nearly close to the 5-Likert scale midpoint.

PFSA Bahirdar hub must advance the availability and variety of pharmaceutical products required by its customers because it is the quality of the logistics service dimension with the least level of satisfaction. PFSA Bahirdar hub should attempt to minimize the lead time when replenishing their customer purchase orders as much as possible and announce as soon as possible the discrepancy they discovered from the purchase order submitted by clients.

\section{Declaration}

\section{- Ethics Approval and Consent To Participate}

Not applicable

\section{- Consent for Publication}

Not applicable

\section{- Availability of Data and Materials}

All data generated or analyzed during this study are included in this published article.

\section{- Competing Interests}

The authors declare that he has no competing interests.

\section{- Funding}

There was no funder for this study

\section{- Authors' Contributions}

The idea of doing this study was conceived by BB. Besides, the data collection, analysis, and interpretation were carried out by BB. BB, BK, and ME participated in the writing and approval of the manuscript before submission.

\section{Acknowledgments}

We are thankful to the staff of public health facilities located in the western Gojjam zone for their cooperation and support in providing the requisite data and willingness to provide information through interviews. We would also like to thank all data collectors, as this study would not have been successful without their constructive cooperation.

\section{References}

1. Yannis Politis, Apostolos Giovanis SB (2014) Logistics service quality and its effects on customer satisfaction in the manufacturing companies' supply chains Empirical evidence from Greece. J Model Manag 108(5): 650-668.

2. Mutugi BM (2014) Factors influencing the effectiveness 
of logistics management information systems in public health sector: A case study of Kenya medical supplies authority pp: 1-68.

3. Tilahun A, Geleta DA, Abeshu MA, Geleta B (2016) Assessment of Integrated Pharmaceutical Logistic System for the Management HIV/AIDS and Tuberculosis Laboratory Diagnostic Commodities in Public Health Facilities in Addis Ababa, Ethiopia. J Pharma Care Heal Sys 3(2): 1-10.

4. Tilahun A (2014) Assessment of Integrated Pharmaceutical Logistics System for Human Immunodeficiency Virus/Acquired Immunodeficiency Syndrome (HIV/ AIDS) and Tuberculosis (TB) Laboratory Diagnostic Commodities management in Public Health Facilities pp: 1-83.

5. Gu Y, Dong S (2016) Logistics Cost Management from the Supply Chain Perspective. J Serv Sci Manag 9: 229-232.

6. Turkyilmaz A, Bulak ME, Zaim S (2015) Assessment of TQM Practices as a Part of Supply Chain Management in Healthcare Institutions. Int J Supply Chain Manag 4(4): 1-9.

7. Mensah C, Daniel Diyuoh DO (2014) Assessment Of Supply Chain Management Practices and Its Effects on The Performance of Kasapreko Company. Eur J Logist Purch Supply Chain Manag 2(1): 1-16.

8. Tamashiro HR da S (2011) Quality Service and Customer Satisfaction: A Study In The Retail Pharmaceutical. Rev Metrop Sustentabilidade 2: 41-62.

9. Shou Y (2013) Perspectives on Supply Chain Management in the Healthcare Industry. Atl Press pp: 630-633.

10. Wang W (2016) Cold Chain Logistics Development and Analysis of Necessity. J Serv Sci Manag 9: 238-242.

11. Daniel G, Tegegnework H, Demissie T, Reithinger R (2012) Pilot assessment of supply chains for pharmaceuticals and medical commodities for malaria, tuberculosis, and HIV infection in Ethiopia. Trans R Soc Trop Med Hyg 106(1): 60-62.

12. Standard Operating Procedures (SOP) Manual for the Integrated Pharmaceuticals Logistics System in Health Facilities of Ethiopia. In: ${ }^{\text {nd }}$ (Edn.), Pharmaceuticals Fund and Supply Agency pp: 124.

13. Mekonen DT (2015) The Study of Ethiopia Public Health Supply Chain Management: Before and After Pharmaceuticals Fund and Supply Agency.

14. Getachew N, Ensermu M (2017) Assessment of Integrated
Pharmaceutical Logistics System (IPLS) in Public Health Facilities at East Wollega Zone.

15. Abiy S, Dowling P, Necho W, Sami Tewfik YY (2015) Ethiopia: National Survey of the Integrated Pharmaceutical Logistics System. USAID, Deliv Proj, pp: 1-84.

16. $\mathrm{MOH}$ (2006) National Pharmacy Service,Pharmaceuticals Supply Chain, and Medical Equipment Management Monitoring and Evaluation Framework pp: 1-67.

17. Lee Don, Hee KKK (2017) Assessing healthcare service quality: a comparative study of patient treatment types. Int J Qual Innov 3(1): 1-18.

18. Thai VV (2013) Logistics service quality: Conceptual model and empirical evidence. Int J Logist Res Appl 16(2): 114-131.

19. USAID (2008) Deliver Project. Task Order 1. Logistics Indicators Assessment Tool (LIAT). Arlington, pp: 1-42.

20. FDRE (2014) National Research Ethics Review Guideline. FDRE Ministry of Science and Technology. Addis Ababa, Ethiopia. In: $5^{\text {th }}$ (Edn.), pp: 95.

21. Devi PUM, Rao BS, Rajashekar PB, Bhaskar NU (2014) Evaluation-of-Service-Quality-from-DistributorsPerspective. Int J Sci Eng Res 5(11): 1024-1035.

22. Hana Alemu BD (2016) Implication Of Logistics Service Quality On Customer Satisfaction: The Case of Jumia Online Market pp: 1-76.

23. Fugate BS, Stank TP (2019) Logistics Performance: Efficiency, Effectiveness, and Differentiation Brian S Fugate. J Bus Logistics 3(1): 43-62.

24. Pavithira S, Subathira R, Subramani A (2015) Customer satisfaction towards apollo pharmacy, Ambattur, Chennai. Zenith Int J Multidiscip Res 5(6): 13-23.

25. Tawfiq Masroujeh WF (2009) Critical Factors for Customer Satisfaction and Delight in the Palestinian Pharmaceutical Market. pp: 1-127.

26. Joshy KT, Peterkumar FJ, Vakayil S (2020) The impact of service quality on customer satisfaction; an empirical study. Int J Manag 11(3): 76-88.

27. Omar R, Ramayah T, Lo M, Sang TY, Siron R (2010) Information sharing, information quality, and usage of information technology (IT) tools in Malaysian organizations. African J Bus Manag 4(12): 2486-2499.

28. Zewdie A, Wabe N (2012) The prevalence of therapeutic 
injections in Ethiopia: from the patients, and health care providers perspectives. Gaziantep Med J 18(1): 21.

29. Sado E, Sufa A (2016) Availability and affordability of essential medicines for children in the Western part of Ethiopia: Implication for access. BMC Pediatr 16(1): 1-8.

30. Kotwani A (2013) Where are we now: Assessing the price, availability, and affordability of essential medicines in Delhi as India plans free medicine for all. BMC Health Serv Res 13(1): 1.

31. Xi X, Li W, Li J, Zhu X, Fu C, et al. (2015) A survey of the availability, prices, and affordability of essential medicines in Jiangsu Province, China. BMC Health Serv Res 15(1): 1-7.

32. Kefale AT, Shebo HH (2019) Availability of essential medicines and pharmaceutical inventory management practice at health centers of Adama town, Ethiopia. BMC Health Serv Res 19(1): 1-7.

33. Simon A, Kotei JA (2014) Supply Chain Management of the Pharmaceutical Industry for Quality Health Care Delivery: Consumer Perception of Ernest Chemists Limited as a Pharmaceutical Service Provider in Ghana. J Inf Eng Appl 4(8): 15-40.

34. Yousefi N, Alibabaei A (2015) Information flow in the pharmaceutical supply chain. Iran J Pharm Res 14(4): 1299-1303.

35. Li X (2014) Operations management of logistics and supply chain: Issues and directions. Discret Dyn Nat Soc 2014: 1-8. 